\title{
It Is Time to Meet the Challenges of the Changing Epidemiology of Gastroesophageal Reflux Disease
}

\author{
Gwang Ha Kim \\ Department of Internal Medicine, Pusan National University School of Medicine, and Biomedical Research Institute, Pusan National University \\ Hospital, Busan, Korea
}

Article: The changing epidemiology of gastroesophageal reflux disease: are patients getting younger?

Yamasaki T, Hemond C, Eisa M, Ganocy S, Fass R

(J Neurogastroenterol Motil 2018;24:559-569)

Gastroesophageal reflux disease (GERD) is a condition in which the reflux of gastric content into the esophagus leads to troublesome symptoms and/or complications. It is a very common condition, and its prevalence has continued to increase since the turn of the last century. The risk of developing Barrett's esophagus (BE) increases linearly with an earlier onset as well as with the frequent and longer durations of GERD symptoms, ${ }^{1}$ thus suggesting the importance of age of onset in the pathogenesis of GERD. Although most epidemiological studies have demonstrated an increased prevalence of GERD in the aging population, ${ }^{2}$ a consistent trend has not been detected. In a survey by the Gallup Organization, $22 \%$ of the respondents older than 50 years used antacids and anti-dyspepsia medications 2 or more times in a week, whereas only $9 \%$ of the respondents younger than 50 years used these medications 2 or 3 times in a week. ${ }^{3}$ Another study of 11945 patients with GERD and erosive esophagitis in the United States (US) indicated a progressive increase in the prevalence of severe erosive esophagitis with each decade of age. ${ }^{4}$ A cohort study of 29610 individuals, conducted from 1995 to 1997 and from 2006 to 2009 in Norway, revealed that increasing age was weakly but positively associated with new-onset GERD. ${ }^{5}$ Similarly, a recent US study based on the Cerner Health Facts database (including 35000000 patients from January 2001 to December 2010), showed an increasing trend in the prevalence of GERD, BE, and esophageal adenocarcinoma (EAC) with increasing age. ${ }^{6}$ On the contrary, a US study conducted with 476 individuals, which mainly included male veterans who were undergoing endoscopy for upper gastrointestinal symptoms, showed that the prevalence and severity of esophagitis was similar in elderly ( $>65$ years) and young $\left(<65\right.$ years) patients. ${ }^{7}$ In another US study, including 2200 residents of Olmsted County, Minnesota, aged 25-74 years, the prevalence of typical GERD symptoms (heartburn or acid regurgitation) did not significantly increase with advancing age. ${ }^{8}$ However, most of these epidemiologic studies estimated the prevalence, and not the incidence, of GERD. Since prevalence estimates included all GERD patients in the study period without considering whether the disease started at an earlier age, a higher cumulative rate of GERD (a cohort effect) could have resulted in an increase in the observed prevalence rate of GERD in

Received: September 7, 2018 Revised: None Accepted: September 13, 2018

() This is an Open Access article distributed under the terms of the Creative Commons Attribution Non-Commercial License (http://creativecommons. org/licenses/by-nc/4.0) which permits unrestricted non-commercial use, distribution, and reproduction in any medium, provided the original work is properly cited.

*Correspondence: Gwang Ha Kim, MD, PhD Department of Internal Medicine, Pusan National University School of Medicine, and Biomedical Research Institute, Pusan National University Hospital, 179 Gudeok-ro, Seo-gu, Busan 49241, Korea Tel: +82-51-240-7869, Fax: +82-51-244-8180, E-mail: doc0224@pusan.ac.kr 
the elderly.

In this issue of Journal of Neurogastroenterology and Motility, Yamasaki et $\mathrm{al}^{9}$ evaluated the prevalence of GERD using a 11year dataset originating from 26 major Healthcare systems and 360 hospitals in northern Ohio. This analysis showed an increased prevalence of GERD in the aging population, with those in the 6070 years age group and those aged $\geq 70$ years having the highest prevalence rate as compared to all other age groups. Furthermore, they investigated whether GERD was becoming more prevalent in younger populations than in older populations. They noted that despite the increased proportion of patients with GERD in all age groups, except for the $\geq 70$ years age group, the greatest increase was observed in the 30-39 years group. These results are consistent with the current situation, where most clinicians have noticed an increase in the number of visits from young patients with GERD as compared to the past.

Therefore, how can we explain the recent increase in the incidence of GERD in the younger age group? The possible mechanisms for increased incidence of GERD in the elderly population include weakened and impaired esophageal motility, decreased salivary and bicarbonate secretions, decreased lower esophageal sphincter pressure with advancing age, diaphragmatic weakness, increased incidence of hiatal hernia, presence of comorbidities such as diabetes and Parkinson disease, and concomitant use of medications such as nitrates, calcium antagonists, theophylline, or antidepressants. ${ }^{3}$ However, these mechanisms cannot explain the increased incidence of GERD in the younger population. The increased incidence of obesity, decreased prevalence of Helicobacter pylori infection, smoking, and heavy alcohol consumption can explain the recent increase in the incidence of GERD in the young age group. ${ }^{3}$ In particular, the increasing rates of obesity coupled with declining rates of $H$. pylori infection are the likely reasons behind the observed increase in the incidence of early onset GERD. Obesity is a major risk factor for GERD symptoms, with an odds ratio of $1.73 .{ }^{10}$ A reduction in the body mass index by at least $3.5 \mathrm{~kg} / \mathrm{m}^{2}$ increases the odds for disappearance of GERD symptoms by 1.5 - to 2.4 -fold. ${ }^{11}$ Pooled data suggest that $H$. pylori infection results in gastric atrophy and decreased gastric acid secretion, indicating that $H$. pylori infection has a preventive effect on the occurrence of GERD. ${ }^{12}$ Therefore, a decrease in the incidence of $H$. pylori infection in young age, due to an improvement of sanitary conditions and early $H$. pylori eradication therapy, may have a role in the increased incidence of GERD as a result of normalization of gastric acid secretion.

What is the clinical significance of the increase in the prevalence of GERD in the younger age group? There are two aspects to be considered here; the natural course of GERD and proton pump inhibitor (PPI) treatment duration. Firstly, the prolonged duration of GERD symptoms, especially with high frequency and severity, are strongly associated with an increased risk of $\mathrm{BE}$ and $\mathrm{EAC}{ }^{13}$ Even though BE and EAC are rare in the first 3-4 decades of life, age of $<30$ years at onset of frequent GERD symptoms is reported to be associated with a high risk of developing $\mathrm{BE}$ (odds ratio, $15.1 ; 95 \%$ confidence interval, 7.9 to 28.8 ), and the risk increased linearly with younger age at onset of GERD symptoms. ${ }^{14}$ Second, because young GERD patients consume more PPIs, the possibility of adverse effects of PPIs, such as chronic kidney disease, osteoporosis, gastrointestinal infection, and pneumonia increases concurrently. ${ }^{15}$ Yamasaki et $\mathrm{al}^{9}$ also showed that the proportion of GERD patients who were using PPIs increased in all age groups, except for the $\geq 70$ years group, with the greatest increase being in the $30-39$ year age group.

It is true that, currently, the proportion of young GERD patients is continuously increasing. It means that we must prepare to manage the complications of GERD and the adverse effects of PPIs that these patients may encounter in the future. For this, clinicians need to have a comprehensive knowledge regarding the systematic surveillance needed to manage the complications of GERD, as well as knowledge regarding the proper use of PPIs. It is also important that clinicians establish a detailed line of communication with their patients.

\section{Financial support: None.}

\section{Conflicts of interest: None.}

\section{References}

1. Balasubramanian G, Singh M, Gupta N, et al. Prevalence and predictors of columnar lined esophagus in gastroesophageal reflux disease (GERD) patients undergoing upper endoscopy. Am J Gastroenterol 2012;107:1655-1661.

2. Achem SR, DeVault KR. Gastroesophageal reflux disease and the elderly. Gastroenterol Clin North Am 2014;43:147-160.

3. Bashashati M, Sarosiek I, McCallum RW. Epidemiology and mechanisms of gastroesophageal reflux disease in the elderly: a perspective. Ann N Y Acad Sci 2016;1380:230-234.

4. Johnson DA, Fennerty MB. Heartburn severity underestimates erosive esophagitis severity in elderly patients with gastroesophageal reflux disease. Gastroenterology 2004;126:660-664.

5. Hallan A, Bomme M, Hveem K, Møller-Hansen J, Ness-Jensen E. Risk factors on the development of new-onset gastroesophageal reflux symptoms. A population-based prospective cohort study: the HUNT 
study. Am J Gastroenterol 2015;110:393-400.

6. Petrick JL, Nguyen T, Cook MB. Temporal trends of esophageal disorders by age in the Cerner Health Facts database. Ann Epidemiol 2016;26:151-154, e4.

7. Triadafilopoulos G, Sharma R. Features of symptomatic gastroesophageal reflux disease in elderly patients. Am J Gastroenterol 1997;92:2007-2011.

8. Locke GR 3rd, Talley NJ, Fett SL, Zinsmeister AR, Melton LJ 3rd. Prevalence and clinical spectrum of gastroesophageal reflux: a population-based study in Olmsted County, Minnesota. Gastroenterology 1997;112:1448-1456.

9. Yamasaki T, Hemond C, Eisa M, Ganocy S, Fass R. The changing epidemiology of gastroesophageal reflux disease: are patients getting younger? J Neurogastroenterol Motil 2018;24:559-569.

10. Eusebi LH, Ratnakumaran R, Yuan Y, Solaymani-Dodaran M, Bazzoli F, Ford AC. Global prevalence of, and risk factors for, gastro-oesophageal reflux symptoms: a meta-analysis. Gut 2018;67:430-440.

11. Ness-Jensen E, Hveem K, El-Serag H, Lagergren J. Lifestyle intervention in gastroesophageal reflux disease. Clin Gastroenterol Hepatol 2016;14:175-182, e1-e3.

12. Kandulski A, Malfertheiner P. Helicobacter pylori and gastroesophageal reflux disease. Curr Opin Gastroenterol 2014;30:402-407.

13. Boeckxstaens G, El-Serag HB, Smout AJ, Kahrilas PJ. Symptomatic reflux disease: the present, the past and the future. Gut 2014;63:11851193.

14. Thrift AP, Kramer JR, Qureshi Z, Richardson PA, El-Serag HB. Age at onset of GERD symptoms predicts risk of Barrett's esophagus. Am J Gastroenterol 2013;108:915-922.

15. Vaezi MF, Yang YX, Howden CW. Complications of proton pump inhibitor therapy. Gastroenterology 2017;153:35-48. 